\title{
Comparison of Fructose and Glycerol as Plasticizers in Cassava Bioplastic Production
}

\author{
Stephen Mukuze*, Hillary Magut, Frankson Lovemore Mkandawire \\ School of Science and Technology, Department of Biological Sciences and Agriculture, \\ University of Eastern Africa Baraton
}

*Corresponding Author email:
mukuzest@ueab.ac.ke

Article History

Received: 16 May 2019

Revised: 30 Jun 2019

Accepted: 07 July 2019

Published: 08 July 2019

Student(s)

- $\quad$ Stephen Mukuze

Academic Year: 2018-19, $1^{\text {st }}$ Semester

Course Level: Bachelor

Course Name: Agriculture

Course year: $3^{\text {rd }}$ year

Mentor(s)

- Hillary Magut

- Frankson Lovemore Mkandawire

\begin{abstract}
ABSTRA C T
This research paper is an investigation into the effects of fructose and glycerol as plasticizers in cassava bioplastic production. The experiments were carried out at the University of Eastern Africa, Baraton Department of Chemistry. The objectives of the research were to produce cassava-based bioplastics in the University of Eastern Africa, Baraton Chemistry Department Laboratory, to investigate the use of fructose and glycerol as plasticizers in the production of the cassava-based bioplastics and to conduct physical and chemical quality tests on the bioplastics to determine which plasticizer is best for industrial use. A Randomized Complete Block Design (RCBD) was used in the experiments. The parameters measured were film thickness, density, moisture content, solubility in water, water absorption, swelling index, and biodegradability test. Overall, fructose as a plasticizer is recommended over glycerol and over fructose and glycerol.
\end{abstract}

Keywords: Plasticizer, Glycerol, Fructose, Cassava, Bioplastic, Biopolymer

\section{Introduction}

Cassava (Manibot esculenta Crant:) is the third major source of carbohydrate in the world and has a wide range of uses and serves as food security for millions of people living in the developing world, however the waste from cassava processing plants is disposed of into landfills which degrade the soil as the waste contains cyanide which increases acidity of the soil and kills soil microorganisms on the dump site making the land unsuitable for agricultural use as discussed by Obueh and Odesiri-Eruyteyan [1]. Cassava is also used in the paper industry, food industry, textile industry, feed industry, in making wood furniture, foundry and in well drilling according to Save and Grow Cassava [2]. Since there is a ban on the use of synthetic plastics in Kenya, imposed on Monday 28 August 2017 as stated by Board [3], in an effort to reduce the accumulation of synthetic plastics in the environment, there is an opportunity for cassava farmers to produce bioplastics to meet the gap in packaging and carrying material while simultaneously reducing the toxic effects of cyanide in cassava waste on the soil. Cassava peel waste is one of the raw materials used in making environmentally friendly bioplastic as it is available in large amounts and does not compete with humans and animals for food as explained by Fathanah et al [4]. Unfortunately, bioplastics are unstable and 
do not have the same tensile strength as synthetic plastic hence the adoption of the technology has been slow, however, plasticizers give the cassava bioplastic the tensile strength that is lacking according to Hongbo and Huneault [5]. This research project takes a look at two of the most popular plasticizers used to give tensile strength to biopolymers which are glycerol and fructose, polyols commonly used as thermoplastic starch plasticizers as they are both FDA-approved as food additives as further explained by Hongbo and Huneault [5]. Bioplastics, in the absence of a plasticizer, are brittle and unstable but plasticizers improve stability, water resistance and enable packaging and industrial applications according to Vieira et al [6]. Glycerol and fructose have been compared and contrasted in several types of thermoplastics there has not been a comparison with a cassava-based biopolymer being used as a bioplastic. There are several commercial producers of cassava-based bioplastics, however, they have kept their research and finding to themselves. As a result of this, the United Nations Environment Programme (UNEP) is sceptical of bioplastics since research information on the subject is scarce and hence has not endorsed them as discussed by Monks [7].

\section{Literature Review}

\subsection{Cassava Value Chain in Kenya}

Cassava (Manibot esculenta), or manioc, mandioca, and yuca, is a woody perennial in the family (Euphorbiaceae) is a staple crop in the tropics important for food security as stated by Shackelford et al [8]. According to Waisundara, the plant can be grown throughout the year and is known to exist under severe climates and soils that are not fertile [9]. Shackelford et al further adds that cassava also has a high yield of up to $60 \mathrm{t} / \mathrm{ha}$ [8]. Because of these benefits, improvements in cassava quality, sustainability, and yield could be important for food security especially in Africa, where the projected population in 2050 is expected to double as explained by the United Nations (UN) [10]. Unfortunately, lack of value addition and processing tools along with a lack of capacity building in production and processing technologies are also contributing factors as to why cassava processing and marketing remain unexploited in Kenya according to Abong et al [11]. The processing of cassava peel waste into bioplastic in Kenya would increase the country's food security as production would have increased to meet demand while simultaneously adding value to the crop through processing tools and technologies needed to manufacture the bioplastic says Bramel et al [12]. It is therefore important to develop new high yielding cassava varieties, with small-granule mutations and waxystarch quality traits that have high demand in industrial markets states the International Center for Tropical Agiculture (CIAT) [13].

\subsection{Cyanide and Cassava}

Hydrogen cyanide is released from cyanogenic glycosides when cassava is broken down by enzymes thus causing a great concern on how cassava is used as food, feed, and industrial raw material states the Food and Agriculture Organization (FAO) [14]. The cyanide level of cassava can be up to $1000 \mathrm{ppm}$ with sweet cassava having lower levels of cyanide than bitter cassava which is higher than the $10 \mathrm{ppm}$ safe level set by the World Health Organisation (WHO) as described by Ndubuisi and Chidiebere [15]. Cyanide in cassava is toxic to both humans and animals and can cause death, however, processing reduces cyanogenic compounds to a safe level below $10 \mathrm{ppm}$ and cassava can be processed into crisps, flour, and other culinary products according to Abong [11]. Conventional cassava processing, however, generates solid and liquid residues or waste that are hazardous to the environment such that when dumped into water bodies, the toxic cassava effluent causes oxygen depletion which results in the death of aquatic life which is why processing into bioplastics is a promising approach as described by Obueh and Odesiri-Eruteyan[16].

\subsection{Biodegradability and Bioplastics}

A biodegradable compound can be defined as one that is completely used as a source of carbon for microbial growth as stated by Harrison et al [17]. Synthetic plastics have been widely used because they are lightweight, durable, malleable and low cost, however, they break down at a very slow rate in the 
Mukuze et al., Adv. J. Grad. Res.; Vol. 6, Issue 1, pp: 41-52, July 2019

environment and hence contribute to environmental pollution according to Peplow [18]. Bioplastics are a promising alternative as they decompose by biotic factors and also constitute a source of organic compounds for microorganism though their biodegradability in different environments is highly affected by their chemical and physical structure as described in many reports [19]-[20].

\subsection{Starch}

Starch is a main nutrition component of our main staple crops, including cassava and potato, and has many industrial uses such as a component of biodegradable plastics, and, in order to meet the needs of different functions, starch must have solubility, viscosity, film-forming ability according to Wang et al [21]. Cassava starch is particularly suitable for producing starch of excellent quality because of its low cost and white, sticky and lucent characteristics as stated by Ogunrinola and Akpan [22]. The physical arrangement of amylose $\left(\mathrm{C}_{14} \mathrm{H}_{26} \mathrm{O}_{11}\right)$ and amylopectin $\left(\mathrm{C}_{30} \mathrm{H}_{52} \mathrm{O}_{26}\right)$ as shown in Table 1, their molecular formula which is $370.351 \mathrm{~g} / \mathrm{mol}$ and $828.72 \mathrm{~g} / \mathrm{mol}$ respectively, and the interaction between food components and starch molecules determine the physicochemical properties of starch and in turn, these affect the potential applications of starch and the quality of starch-based products, such as bioplastics as described by Ahmed et al [23]. Starch-based bioplastics have a few limitations such as their highly hydrophilic state, which negatively affects barrier and tensile properties when compared with synthetic plastics, therefore, different approaches, such as blending must be investigated to improve these characteristics according to Sapper $e t$ al [24].

Table 1: Chemical Properties of Starch Macromolecules (Pubchem.ncbi.nlm.nih.gov, 2018)

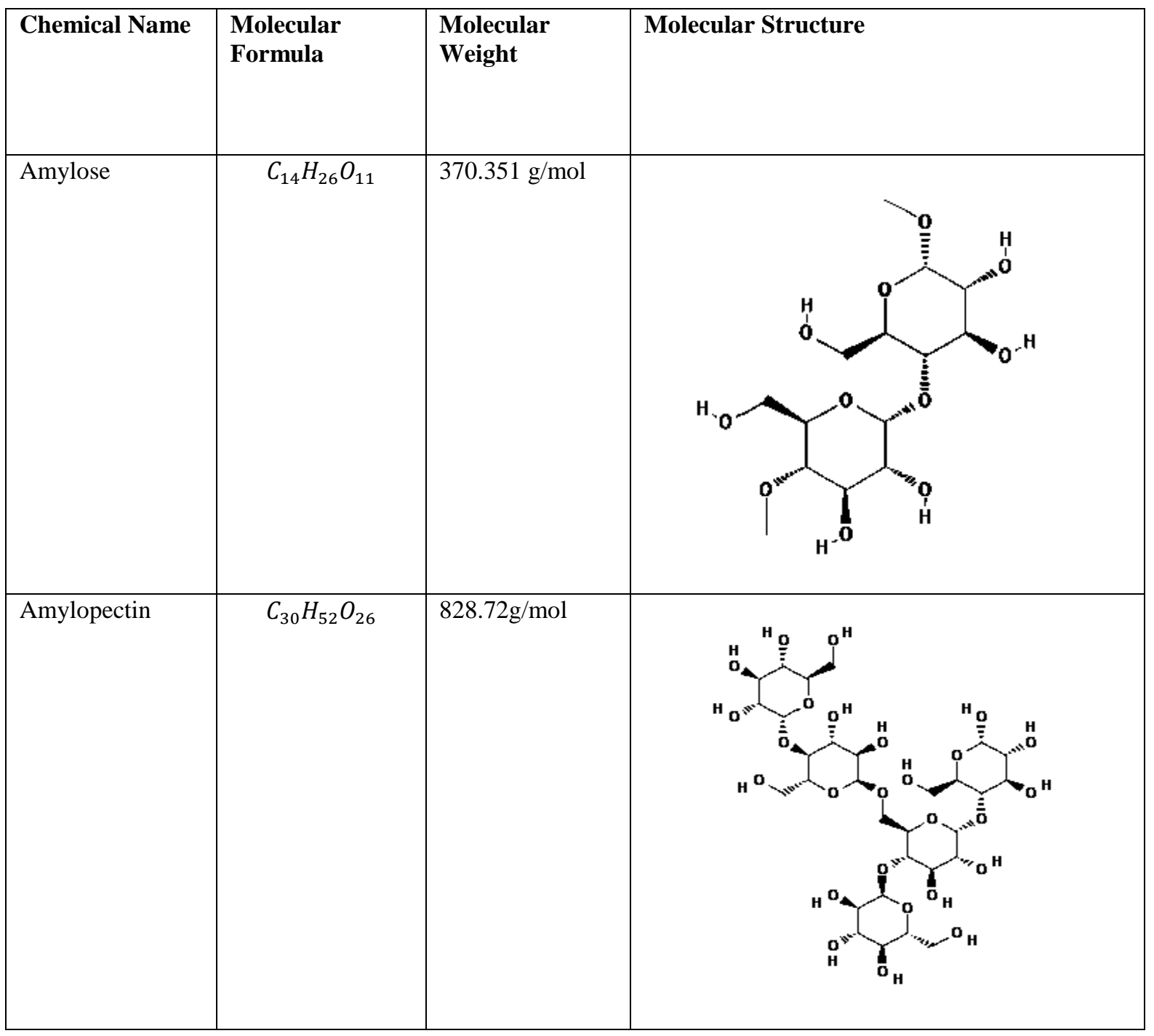




\subsubsection{Starch/Polymer Blends}

Starch as a polymer containing a continuous chain of amylose and branched chain amylopectin cannot form a real thermoplastic by itself, but, in the presence of a plasticizer (water, glycerol, fructose, sorbitol), high temperature and shearing it fluidized and melts it, thus allowing for its processability into mould and blowing just like conventional plastic as stated by Ogunrinola and Akpan [22].

\subsection{Plasticizers}

Plasticizers are colourless and odourless esters, mainly phthalates, which increase the elasticity of a material according to Koester [25]. Starch-based polymers are known to have poor mechanical properties and are notoriously brittle resulting in the need to incorporate a plasticizer, whereby, the primary function of plasticizers is to increase mobility of polymer chains by reducing their intermolecular forces, which help to increase flexibility and decrease glass transition temperature of the plasticized starch materials according to Edhirej et al [26]. Plasticizers enhance the desired mechanical characteristics of bioplastic film, and the commonly used plasticizers in starch-based films are glycerol and sorbitol as stated by Jantrawut et al [27]. Plasticizers are important in the production of bioplastics because they increase its flexibility and workability, however, they result in lower hardness as described by Maliuda et al [28].

\subsubsection{Fructose and Glycerol}

Fructose whose molecular formula is $\mathrm{C}_{6} \mathrm{H}_{12} \mathrm{O}_{6}$ and whose molecular weight is $180.156 \mathrm{~g} / \mathrm{mol}$ as shown in Table 2, is a fruit sugar found in fruit juices and honey and differs from glucose in having a ketonic rather than an aldehydic carbonyl group as stated by PubChem [29]. PubChem further states that glycerol whose molecular formula is $\mathrm{C}_{3} \mathrm{H}_{8} \mathrm{O}_{3}$ and whose molecular weight is $92.094 \mathrm{~g} / \mathrm{mol}$ as shown in Table 2, is a colourless and odourless non-toxic polyol compound that has three hydroxyl groups that causes its water solubility and its hygroscopic nature [30]. Both glycerol and fructose are FDA-approved as food additives and interact strongly with starch by forming hydrogen bonds with amylopectin and amylose making them effective plasticizers for starch according to the U.S. Food and Drug Administration (FDA) [31].

Table 2: Chemical Properties of Fructose and Glycerol (Pubchem.ncbi.nlm.nih.gov, 2018)

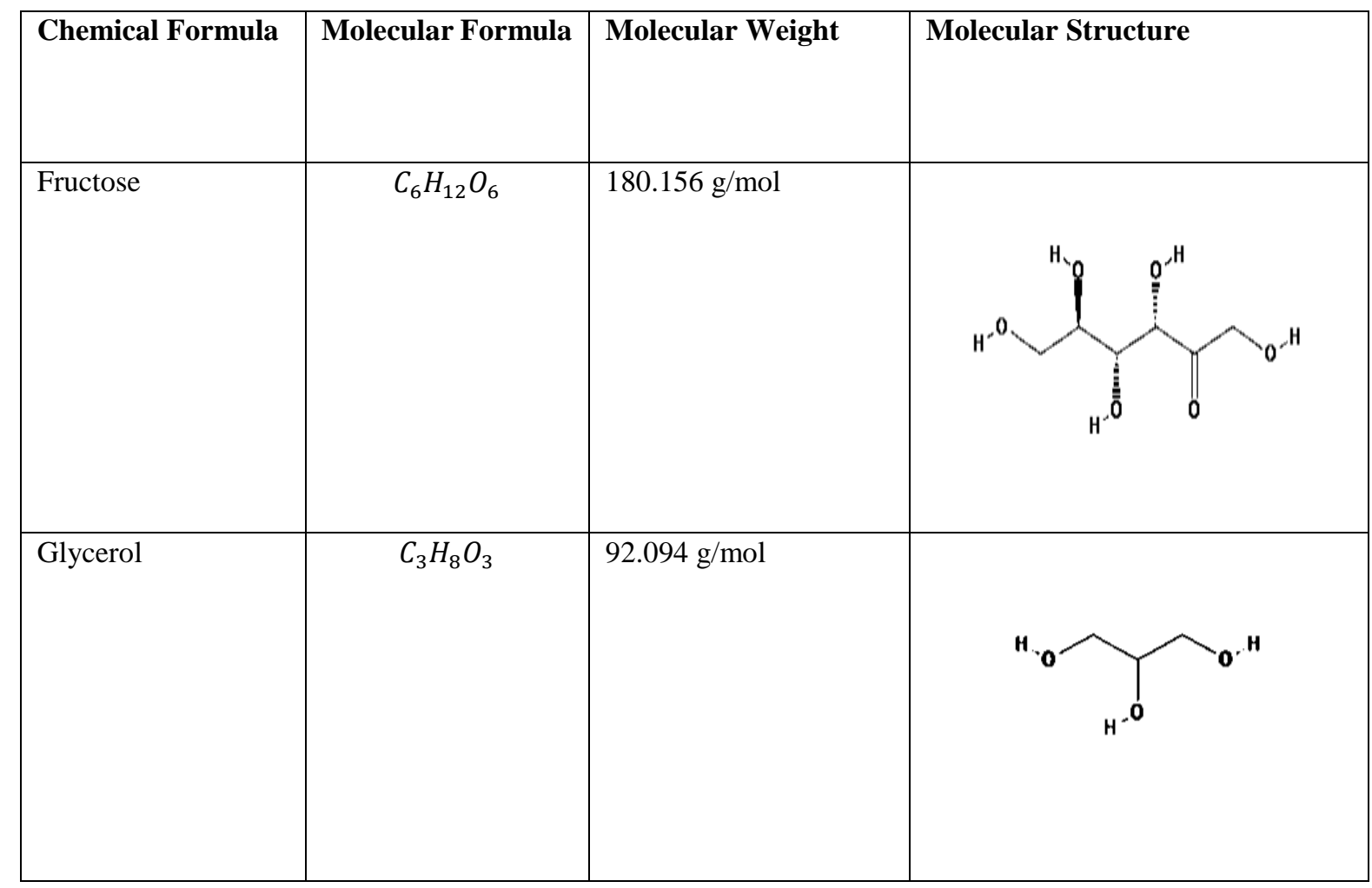




\section{Materials and Methods}

\subsection{Extracting Starch}

The experiments were conducted at the University of Eastern Africa, Baraton in the Chemistry Department. Cassava tubers, from cassava obtained from Nairobi, were washed thoroughly to remove mud and dirt. They were then cut into small pieces and peeled with a machete. A cheese grater was then used to shred the peeled tubers. The shredded tubers were dried in an electric drier then placed in $600 \mathrm{~cm}^{3}$ and $800 \mathrm{~cm}^{3}$ beakers. The beakers were weighed and labelled indicating the weight of the beaker and the variety of cassava. Two beakers were used for extracting starch. Distilled water equal to the level of cassava in each beaker was added, allowing the starch to dissolve in the water. The beakers were stirred with a glass rod until a cloudy white precipitate (starch) had formed. The distilled water with dissolved starch was filtered out into another beaker using a tea strainer. The filtration process was repeated three times. The white precipitate was left for 30 minutes to settle and then was decanted to remove excess water. The white sediment (starch) was first filtered then dried using a Buchner suction filter and was collected in a separate beaker. Any remaining water was evaporated by air drying the semi-solid starch until it was solid. The starch was then weighed.

\subsection{Making the Bioplastic Film}

Distilled water $(50 \mathrm{ml})$ was placed in a $50 \mathrm{~cm}^{3}$ graduated cylinder. Cassava starch $(7.5 \mathrm{~g})$ was and placed in a $50 \mathrm{~cm}^{3}$ beaker. White vinegar $(5 \mathrm{ml})$ was placed in a $5 \mathrm{~cm}^{3}$ graduated cylinder. Food colouring (2 drops) was added to $2 \mathrm{ml}$ of distilled water in a $5 \mathrm{~cm}^{3}$ graduated cylinder. Glycerol/fructose/glycerol and fructose $(7.5 \mathrm{~g})$ were placed in a $500 \mathrm{~cm}^{2}$ beaker. Cooking oil was smeared on the upper surface of a watch glass. The beaker with the plasticizer was placed on top of a hot plate. All the other reagents were placed in this beaker then heated. The beaker was stirred continuously using a glass rod until the solution had become viscous and clear. The viscous solution was poured and smeared evenly on the watch glass with a glass rod while a Bunsen burner flame was passed over it to pop as many bubbles as possible. The viscous solution was then left to air dry.

\subsection{Data Analysis}

Data was collected and analysed using Microsoft Excel (2013), Microsoft Word (2013) and IBM SPSS Statistics for Windows, version 23.

\subsection{Experimental Design}

As shown in Table 3, A Randomized Complete Block Design (RCBD) was used. Four treatments $\left(\mathrm{L}_{1} * \mathrm{~L}_{2} * \mathrm{~L}_{3} * \mathrm{~L}_{4}\right)$ of bitter and sweet cassava were replicated three times.

Table 3: A Randomized Complete Block Design (RCBD)

\begin{tabular}{|l|l|l|l|l|l|l|}
\hline \multirow{2}{*}{ Treatment } & \multicolumn{3}{|l|}{ Bitter Cassava } & \multicolumn{3}{l|}{ Sweet Cassava } \\
\cline { 2 - 8 } & Rep 1 & Rep 2 & Rep 3 & Rep 1 & Rep 2 & Rep 3 \\
\hline $\mathrm{L}_{1}=$ Bioplastic only & 1 & 1 & 1 & 1 & 1 & 1 \\
\hline $\mathrm{L}_{2}=$ Bioplastic with fructose & 1 & 1 & 1 & 1 & 1 & 1 \\
\hline $\mathrm{L}_{3}=$ Bioplastic with glycerol & 1 & 1 & 1 & 1 & 1 & 1 \\
\hline $\mathrm{L}_{4}=$ Bioplastic with fructose and glycerol & 1 & 1 & 1 & 1 & 1 & 1 \\
\hline
\end{tabular}

\subsection{Parameters Measured}

\subsubsection{Film Thickness}

The film thicknesses were determined using a digital micrometre and three random measurements were performed for each film and an average value was calculated as described by Edhirej et al [26]. 


\subsubsection{Film Density}

The mass of each film sample with a film area of approximately $1 \times 1 \mathrm{~cm}^{2}$ was obtained by weighing the film using a standard chemical digital weighing scale accurate to $0.1 \mathrm{~g}$. The film volume was calculated by a water displacement method with a specified weight of the film. The film volume was calculated by multiplying the film area by the thickness as stated in many reports [28]-[32].

$$
\rho=\frac{m}{v}=\mathrm{g} / \mathrm{cm}^{3}
$$

Where: $\rho=$ density, $m=$ mass, and $v=$ volume

\subsubsection{Film Moisture Content}

The moisture content of the film samples was determined by initially weighing each sample using a digital weighing scale. Each film sample was approximately $1 \times 1 \mathrm{~cm}^{2}$. The samples were dried in an oven at $70^{\circ} \mathrm{C}$ for 3 hours and then reweighed. The moisture content of each film sample was calculated by subtracting the initial weight by the final weight, dividing the result by the initial weight, and then multiplying the result by 100 to get a percentage moisture content according to Sanyang et al [33].

$$
\text { Moisture content }=\left[\frac{W_{\mathrm{i}}-W_{f}}{W_{\mathrm{i}}}\right] \times 100
$$

Where: $W_{i}=$ Initial Weight, $W_{f}=$ Final Weight

\subsubsection{Film Solubility in Water}

Film samples with an area of approximately $1 \times 1 \mathrm{~cm}^{2}$ were weighed to determine the initial dry matter of each film. Each sample was immersed in $50 \mathrm{~mL}$ of distilled water under constant agitation for 3 hours at room temperature. After this period, the insoluble portion of the film was air dried for 24 hours. The dried samples were then reweighed to know the weight of the solubilized dry matter. The water solubility (\%) of the films was calculated by subtracting the initial dry weight by the final dry weight, dividing the result by the initial dry weight, and then multiplying the result by 100 to get a percentage as discussed in many reports [32]-[33].

$$
\operatorname{Solubility}(\%)=\left[\frac{W_{\mathrm{i}}-W_{\mathrm{o}}}{W_{\mathrm{i}}}\right] \times 100
$$

$$
\text { Where: } W_{i}=\text { Weight before submersion, } W_{o}=\text { Weight after submersion }
$$

\subsubsection{Film Water Absorption}

Water uptake of film samples was investigated by weighing film samples with an area of approximately $1 \mathrm{x}$ $1 \mathrm{~cm}^{2}$. The samples were then dried at $70{ }^{\circ} \mathrm{C}$ for 3 hours, cooled, and then immediately weighed. The film samples were then submerged in distilled water for 3 hours without agitation. After the immersion period, the samples were then removed from the water and weighed. The percentage water absorption was calculated by subtracting the initial weight by the final weight, dividing the result by the initial weight, and then multiplying the result by 100 to get a percentage as discussed in many reports [28]-[32].

$$
\begin{gathered}
\text { Water absorption(\%) }=\left[\frac{M_{\text {final }}-M_{\text {initial }}}{M_{\text {initial }}}\right] \times 100 \\
\text { Where: } M_{\text {final }}=\text { Final Weight, } M_{\text {initial }}=\text { Initial Weight }
\end{gathered}
$$

\subsubsection{Film Swelling Index}

The film samples with an area of approximately $1 \times 1 \mathrm{~cm}^{2}$ were weighed to find their dry weight. The samples were then immersed in distilled water at room temperature and removed for reweighing every hour for three hours. The percentage water sorption capacity was calculated by subtracting the initial weight by 
Mukuze et al., Adv. J. Grad. Res.; Vol. 6, Issue 1, pp: 41-52, July 2019

the final weight, dividing the result by the initial weight, and then multiplying the result by 100 to get a percentage according to Sanyang et al [33].

$$
\begin{gathered}
\text { Swelling index }(\%)=\left[\frac{M_{\text {Swollen }}-M_{\text {Dry }}}{M_{\text {Dry }}}\right] \times 100 \\
\text { Where: } M_{\text {Swollen }}=\text { Swollen Weight, } M_{\text {Dry }}=\text { Dry Weight }
\end{gathered}
$$

\subsubsection{Biodegradability Test}

The biodegradability of the film samples was investigated by visual analysis changes and measuring the weight of the samples before and after the films were buried in soil, under natural environmental conditions. Each film sample was approximately $3 \times 1 \mathrm{~cm}^{2}$. The film samples were half buried in $1.5 \mathrm{~cm}$ of ordinary soil resulting in half a sample being buried while half being exposed to the open air. One film sample was removed from the soil after a week, cleaned by wiping gently with a brush, inspected, air-dried for another week, inspected again and weighed. The percentage weight loss was calculated by subtracting the initial weight by the final weight, dividing the result by the initial weight, and then multiplying the result by 100 to get a percentage according to Edhirej et al [32].

$$
\text { Weight } \operatorname{loss}(\%)=\frac{W_{\mathrm{i}}-W_{f}}{W_{\mathrm{i}}} \times 100
$$

$$
\text { Where: } W_{i}=\text { Initial Weight, } W_{f}=\text { Final Weight }
$$

\section{Results}

\subsection{Film Thickness}

As shown in Table 4: Cassava Film Thickness, bitter cassava bioplastic with glycerol and bitter cassava bioplastic with no plasticizer had the greatest film thickness for bitter cassava. The tests were conducted twice in order to get averages to be used for one-way ANOVA calculation. To test for the significant difference between the means, one-way ANOVA was applied. The p-value was 0.140 which is greater than the alpha value of 0.05 and therefore the difference between the means is not statistically significant.

Table 4: Cassava Film Thickness

\begin{tabular}{|l|l|l|l|l|l|l|}
\hline \multirow{2}{*}{ Bioplastic } & \multicolumn{3}{|c|}{$\begin{array}{c}\text { Bitter Cassava Thickness } \\
\left(\mathbf{c m}^{\mathbf{3}}\right)\end{array}$} & \multicolumn{3}{|c|}{ Sweet Cassava Thickness } \\
& \multicolumn{3}{|c|}{$\left.\mathbf{c m}^{\mathbf{3}}\right)$} \\
\cline { 2 - 8 } & Test 1 & Test 2 & Test 3 & Test 1 & Test 2 & Test 3 \\
\hline $\mathrm{L}_{1}=$ Bioplastic only & 0.9 & 0.9 & 0.8 & 0.8 & 0.8 & 0.8 \\
\hline $\mathrm{L}_{2}=$ Bioplastic with fructose & 0.8 & 0.8 & 0.7 & 0.6 & 0.8 & 0.8 \\
\hline $\mathrm{L}_{3}=$ Bioplastic with glycerol & 0.9 & 0.8 & 0.8 & 0.8 & 0.7 & 0.8 \\
\hline $\mathrm{L}_{4}=$ Bioplastic with fructose and glycerol & 0.8 & 0.8 & 0.7 & 0.8 & 0.8 & 0.7 \\
\hline
\end{tabular}

\subsection{Film Density}

As shown in Table 5: Cassava Film Density, bitter cassava bioplastic with glycerol and bitter cassava bioplastic with no plasticizer had the highest film density in test 1 while bitter cassava bioplastic with both fructose and glycerol had the highest for test 2 .

Table 5: Cassava Film Density

\begin{tabular}{|l|l|l|l|l|l|l|}
\hline \multirow{2}{*}{ Bioplastic } & \multicolumn{3}{|l|}{ Bitter Cassava Density $\left(\mathbf{g} / \mathbf{c m}^{\mathbf{3}}\right)$} & \multicolumn{3}{|c|}{ Sweet Cassava Density $\left(\mathbf{g} / \mathbf{c m}^{\mathbf{3}}\right)$} \\
\cline { 2 - 7 } & Test $\mathbf{1}$ & Test 2 & Test 3 & Test 1 & Test 2 & Test 3 \\
\hline $\mathrm{L}_{1}=$ Bioplastic only & 1.11 & 1.25 & 1.25 & 1.25 & 1.25 & 1.11 \\
\hline $\mathrm{L}_{2}=$ Bioplastic with fructose & 1.25 & 1.25 & 1.43 & 1.67 & 1.25 & 1.11 \\
\hline $\mathrm{L}_{3}=$ Bioplastic with glycerol & 1.11 & 1.25 & 1.25 & 1.25 & 1.43 & 1.25 \\
\hline $\mathrm{L}_{4}=$ Bioplastic with fructose and glycerol & 1.25 & 1.11 & 1.25 & 1.25 & 1.43 & 1.25 \\
\hline
\end{tabular}


The tests were conducted twice in order to get averages to be used for one-way ANOVA calculation. To test for the significant difference between the means, one-way ANOVA was applied. The p-value is 0.681 which is greater than the alpha value of 0.05 and therefore the difference between the means are not statistically significant.

\subsection{Film Moisture Content}

As shown in Figure 1: Film Average Moisture Content, the bitter cassava bioplastic with both glycerol and fructose had the highest average moisture content retention followed by the bitter cassava bioplastic with glycerol. The sweet cassava bioplastic with glycerol had the lowest average moisture content retention followed by the sweet cassava bioplastic with both glycerol and fructose. Bitter cassava bioplastic has a higher average moisture content retention than sweet cassava. This implies that the starch properties in bitter cassava are better at retaining moisture than those in sweet cassava.

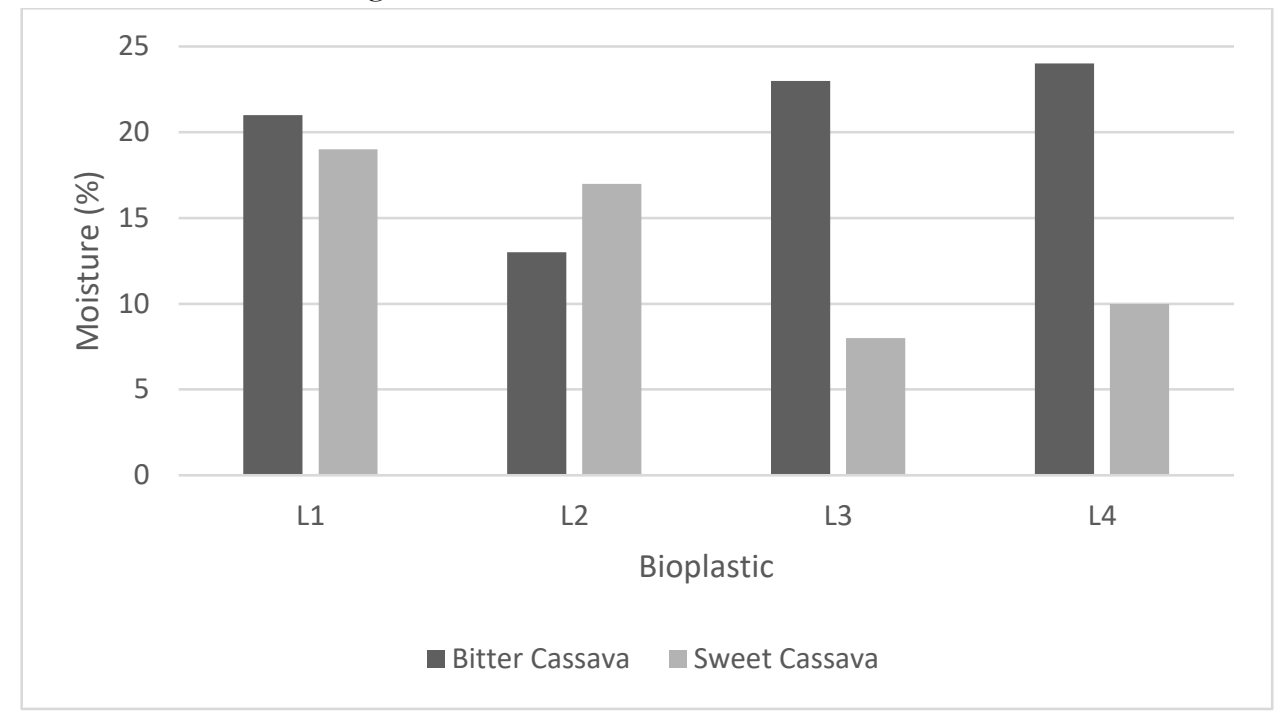

Figure 1: Film Average Moisture Content

\subsection{Film Solubility in Water}

As shown in Figure 2: Film Solubility in Water, the bitter cassava bioplastic with fructose had the highest film average solubility followed by the sweet cassava bioplastic with fructose. The bitter cassava bioplastic with no plasticizer had the lowest film average solubility followed by the sweet cassava bioplastic with fructose. Fructose had the highest film average solubility implying that it is not easily hydrolysed.

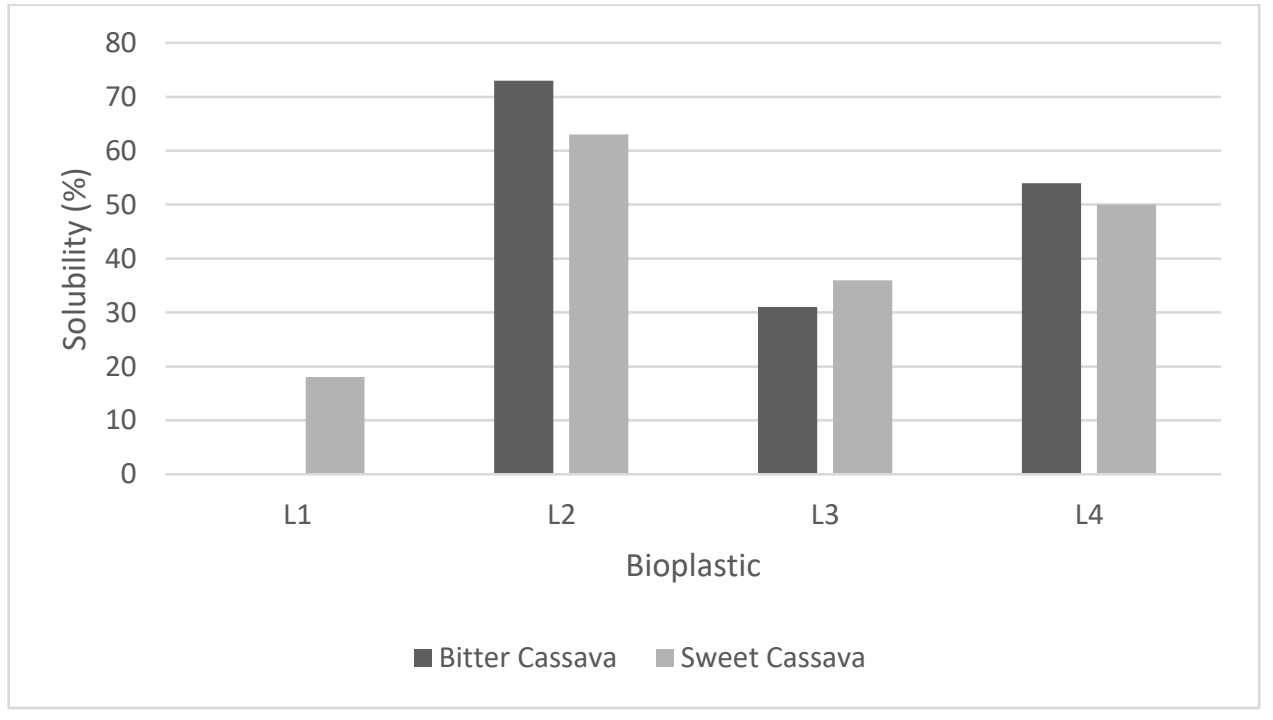

Figure 2: Film Solubility in Water 


\subsection{Film Water Absorption}

As shown in Figure 3: Film Average Water Absorption, both the sweet and bitter cassava bioplastics with no plasticizer had the highest average water absorption. The bitter cassava bioplastic with glycerol had the lowest average water absorption followed by the bitter cassava bioplastic with both plasticizers. This implies that glycerol is the most resistant to water absorption.

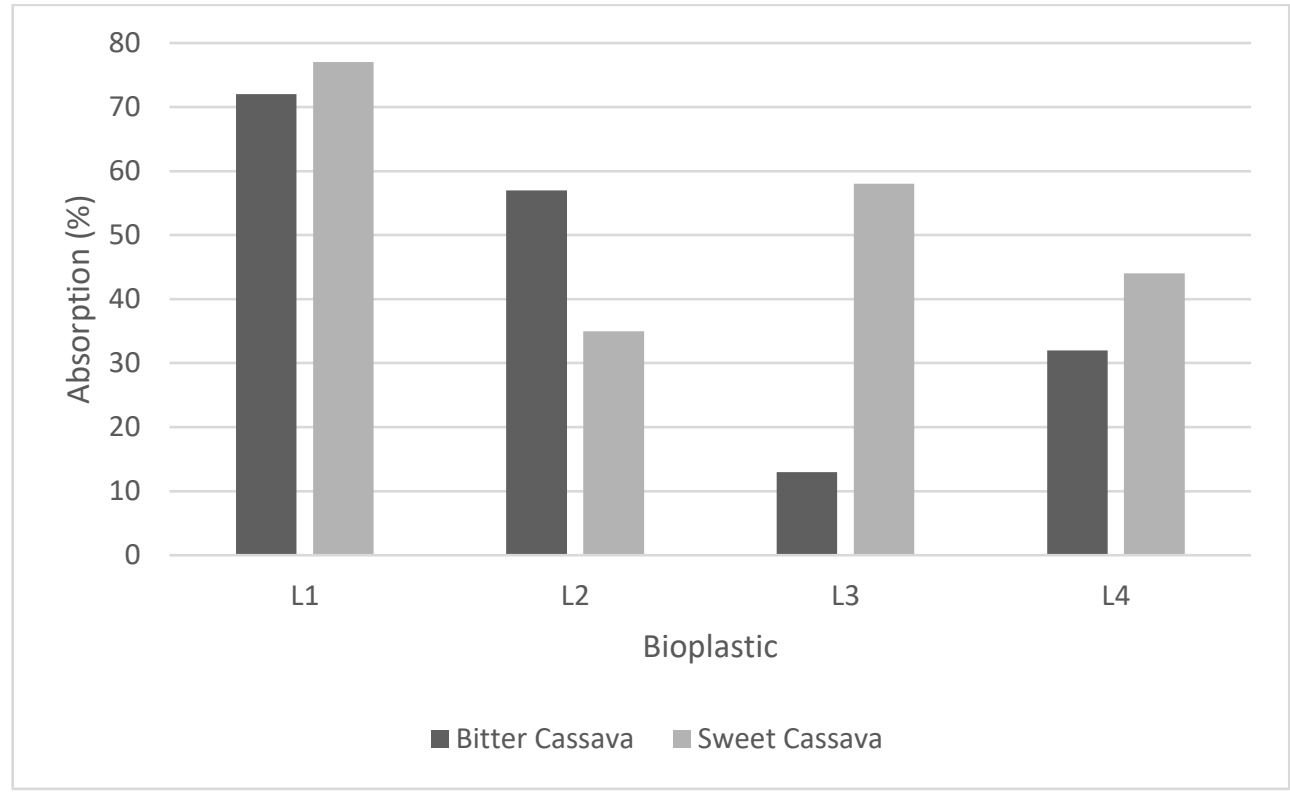

Figure 3: Film Average Water Absorption

\subsection{Film Swelling Index}

As shown in Figure 4: Film Average Swelling Index, both the bitter and sweet cassava bioplastics with no plasticizer had the highest film average swelling index respectively. The bitter cassava bioplastic with fructose had the lowest film average swelling index followed by the sweet cassava bioplastic with both glycerol and fructose. This implies that the bitter cassava bioplastic with fructose has the lowest water resistance.

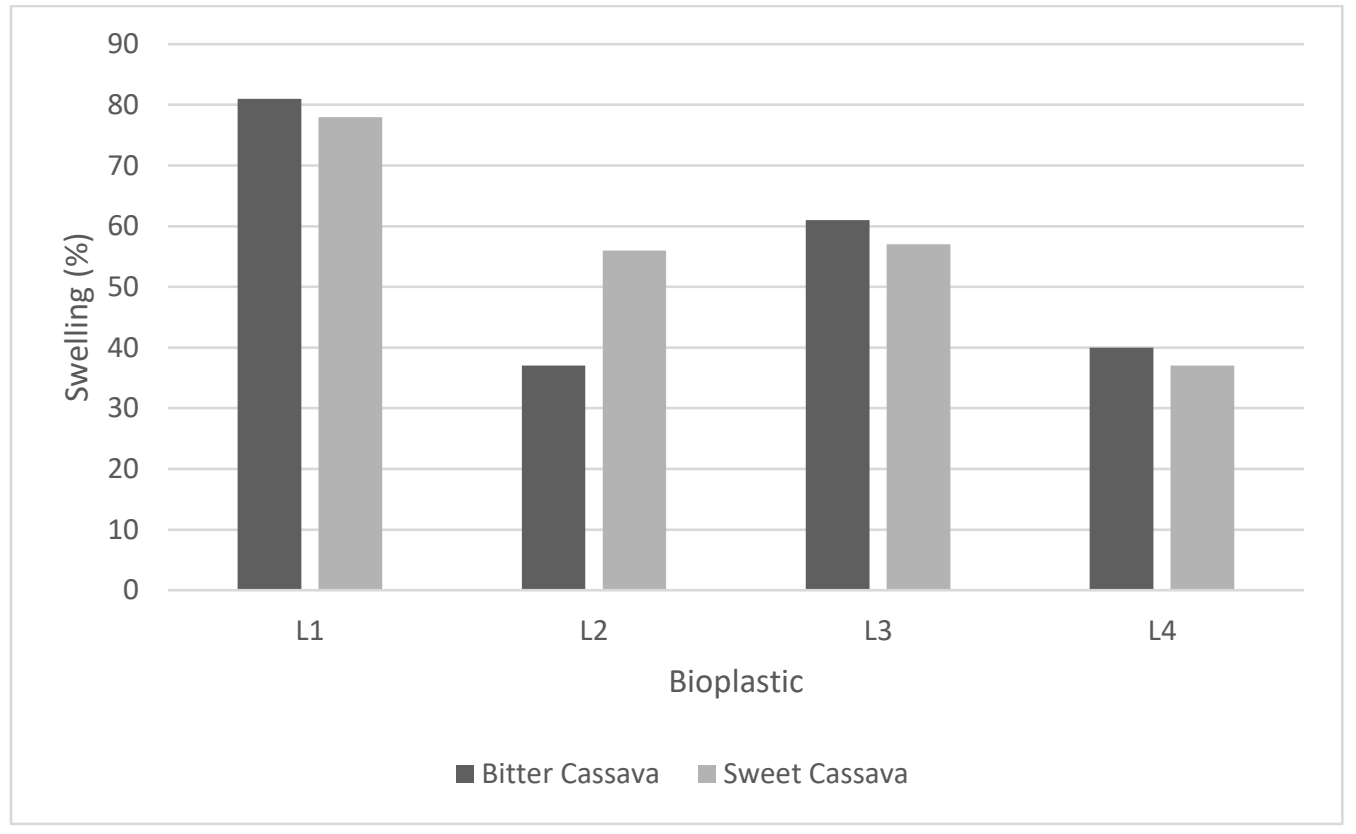

Figure 4: Film Average Swelling Index 


\subsection{Biodegradability Test}

As shown in Table 6: Film Biodegradability test, both the bitter and sweet cassava bioplastic with fructose had the greatest weight loss after fourteen days. The sweet cassava bioplastic with both glycerol and fructose had the least weight loss after fourteen days.

Table 6: Film Biodegradability Test

\begin{tabular}{|l|l|l|l|l|l|l|}
\hline \multirow{2}{*}{ Bioplastic } & \multicolumn{3}{|c|}{ Bitter Cassava Weight (g) } & \multicolumn{3}{c|}{ Sweet Cassava Weight (g) } \\
\cline { 2 - 8 } & $\begin{array}{c}\text { Initial } \\
\text { Weight } \\
(\mathrm{g})\end{array}$ & $\begin{array}{c}\text { Weight }(\mathrm{g}) \\
\text { and \%oss } \\
\text { After 7 } \\
\text { Days }\end{array}$ & $\begin{array}{c}\text { Weight }(\mathrm{g}) \\
\text { and \% Loss } \\
\text { After 14 } \\
\text { Days }\end{array}$ & $\begin{array}{c}\text { Initial } \\
\text { Weight } \\
(\mathrm{g})\end{array}$ & $\begin{array}{c}\text { Weight }(\mathrm{g}) \\
\text { and \% Loss } \\
\text { After 7 } \\
\text { Days }\end{array}$ & $\begin{array}{c}\text { Weight }(\mathrm{g}) \\
\text { and \% Loss } \\
\text { After 14 } \\
\text { Days }\end{array}$ \\
\hline $\mathrm{L}_{1}=$ Bioplastic only & 0.13 & 0.08 & 0.04 & 0.19 & 0.11 & 0.03 \\
\hline $\mathrm{L}_{2}=$ Bioplastic with fructose & 0.58 & 0.35 & 0.03 & 0.48 & 0.25 & 0.05 \\
\hline $\mathrm{L}_{3}=$ Bioplastic with glycerol & 0.30 & 0.22 & 0.10 & 0.24 & 0.18 & 0.08 \\
\hline $\begin{array}{l}\mathrm{L}_{4}=\text { Bioplastic with fructose and } \\
\text { glycerol }\end{array}$ & 0.23 & 0.17 & 0.09 & 0.20 & 0.14 & 0.11 \\
\hline
\end{tabular}

\section{Discussion}

The cassava starch-based bioplastics that were produced were similar, in terms of flexibility and elasticity, to the potato starch-based bioplastics done by Sanyang et al [33]. Descriptive data analysis was performed to explain properties of this cassava-based bioplastic containing fructose plasticizer, glycerol plasticizer, both plasticizers, or no plasticizer. These tests and their results were similar to a combination of various tests done in several experiments [26]-[32]-[33]. For the water retention tests, the fructose plasticizer showed better results than glycerol in the bitter cassava biopolymers, however, the glycerol plasticizer showed better results than fructose in the sweet cassava starch biopolymers. In the water film solubility tests, fructose performed better in both the bitter and sweet cassava biopolymers. In the water absorption tests, fructose performed better than glycerol in the sweet cassava biopolymers, however, glycerol performed better in the bitter cassava bioplastics. The water swelling tests showed that fructose performed better in the bitter cassava bioplastic but was outperformed by glycerol in the sweet cassava bioplastics. In the biodegradability tests, fructose performed better than glycerol in both bitter and sweet cassava biopolymers as it not only had the lowest weights after two weeks but also decomposed faster. These results are similar to those recorded in several reports [34]-[35] with their starch derived from potato and newspaper pulp respectively. The results show that the properties of cassava starch-based bioplastics are similar to those of bioplastics whose starch content has been derived from other sources. The results also show that the effect of fructose, glycerol and fructose and glycerol blend as plasticizers have similar properties on cassava starch-based bioplastics to bioplastics with different starch sources.

\section{Conclusion}

The cassava starch-based bioplastics that were produced were similar, in terms of flexibility and elasticity, to the potato starch-based bioplastics and other bioplastics with different sources of starch done in previous research. Overall, fructose as a plasticizer is recommended over glycerol and over fructose and glycerol because it performed better in the laboratory tests and biodegradability tests. Further analysis with more advanced equipment can be done to give a deeper and more critical understanding of the two plasticizers and the cassava bioplastic produced. Dialysis tubing can also be used to increase the purity of the biopolymer, to remove any monomers and or polymers smaller than a specific size. Size Exclusion Chromatography (SEC) can also be used to provide a desired molar mass distribution result for polymers. 
Mukuze et al., Adv. J. Grad. Res.; Vol. 6, Issue 1, pp: 41-52, July 2019

\section{Declaration}

\subsection{Study Limitations}

The University of Eastern Africa Baraton laboratories lacked some essential equipment needed for Dialysis tubing, Size Exclusion Chromatography (SEC), and Tensile Strength testing. This equipment would have produced a higher quality bioplastic film.

\subsection{Acknowledgements}

Firstly, I would like to express my sincere gratitude to my instructor Mr. F. Mkandawire for the continuous support of my research, for his patience, motivation, and immense knowledge. My thanks and appreciation also go to Mr. H. Magut for persevering with me as my advisor throughout the time it took me to write this research paper. Finally, I would also like to thank Kirika Kivuti, Harry Ochuodho and Arthur Agola for their motivation and assistance in writing this research paper.

\subsection{Funding Source}

None.

\subsection{Competing Interests}

This research was done in collaboration with the Center of Science and Technology Innovation (CSTI).

\section{How to Cite this Article:}

S. Mukuze, H. Magut, and F. Mkandawire, "Comparison of Fructose and Glycerol as Plasticizers in Cassava Bioplastic Production", $A d v$. $J$. Grad. Res., vol. 6, no. 1, pp. 41-52, Jul. 2019. doi: 10.21467/ajgr.6.1.41-52

\section{References}

[1] H, Obueh, and E, Odesiri-Eruteyan. "Study on the effects of cassava processing wastes on the soil environment of a local cassava mill," Journal of Pollution Effects and Control, pp.1-4. Oct, 2016.

[2] Food and Agriculture Organization. "Save and Grow Cassava," Food and Agriculture Organization of the United Nations, pp.3-4. May, 2013. Available at: http://www.fao.org/3/a-i3278e.pdf [Accessed 25 Oct, 2017]

[3] T, Board. "Opinion | Follow Kenya's Lead on Plastic Bags," New York Times. Sep, 2017. Available at: https://www.nytimes.com/2017/09/14/opinion/kenya-plastic-bag-laws.html [Accessed 25 Oct. 2017].

[4] U, Fathanah, M, Lubis, C, Rosnelly, and R, Moulana. "Making and characterizing bioplastic from cassava (Manihot utissima) peel starch with sorbitol as a plasticizer," The 7th International Conference of Chemical Engineering on Science and Applications. pp. 148-154. 2013. Available at: https://rp2u.unsyiah.ac.id/index.php/welcome/prosesDownload/1128/5 [Accessed 25 Oct. 2017]

[5] L, Hongbo, and M, Huneault. "Comparison of sorbitol and glycerol as plasticizers for thermoplastic starch in TPS/PLA blends," Journal of Applied Polymer Science, pp.2439-2448, Sep, 2011.

[6] M, Vieira, M, Silva, L, Santos, and M, Beppu. "Natural-based plasticizers and biopolymer films: a review," European Polymer Journal, Vol 47, Is 3, pp. 254-263, Mar, 2011.

[7] C, Monks. "The plastic bag you can drink," CNN. Jan, 2017. Available at: http://edition.cnn.com/2017/01/16/world/cassavaplastic/index.html [Accessed 25 Oct. 2017].

[8] G, Shackelford, N, Haddaway, H, Usieta, P, Pypers, S, Petrovan and W, Sutherland. "Cassava farming practices and their agricultural and environmental impacts: a systematic map protocol” Environmental Evidence. Dec. 2018.

[9] V, Waisundara. "Introductory Chapter: Cassava as a Staple Food". Intechopen. Jan, 2018.

[10] UN. "World Population Prospects: The 2017 Revision, Key Findings and Advance Tables". United Nations. pp 9-10. 2017. Available at: https://population.un.org/wpp/Publications/Files/WPP2017_KeyFindings.pdf [Accessed 3 Jun. 2018]

[11] O, Abong, S, Shibairo, E, Wanjekeche, J, Ogendo, T, Wambua, P, Lamuka, P, Arama, M, Oko, R, Mulwa, M, Kamidi, Z, Mcosore, and M Katama. "Post-harvest practices, constraints, and opportunities along cassava value chain in Kenya". Research Gate. pp 114126. Aug, 2016.

[12] J, Bramel, E, Witte, R, Asiedu, D, Watson, and R, Okechuckwu. "Expanding the application of cassava value chain technologies through UPoCA project". African Journal of Root and Tuber Crops. pp.1-15. 2013.

[13] CIAT. "Cassava". CIAT. 2018. Available from: https://ciat.cgiar.org/what-we-do/breeding-better-crops/rooting-for-cassava/ [Accessed 3 Jun. 2018]

[14] FAO. "Cassava: A Guide to Sustainable Production Intensification" World Health Organization. pp 3-4. 2013. Available at: http://www.fao.org/3/a-i3278e.pdf [Accessed 3 Jun, 2018]

[15] N, Ndubuisi, and A, Chidiebere. "Cyanide in Cassava: A Review" International Journal of genomics and Data Mining. Feb, 2018.

[16] H, Obueh and E, Odesiri-Eruteyan. "Study on the effects of cassava processing wastes on the soil environment of a local cassava mill". Journal of Pollution Effects and Control. pp.1-4. Oct, 2016.

[17] J, Harrison, C, Boardman, K, O'Callaghan, A, Delort, and J, Song. "Biodegradability standards for carrier bags and plastic films in aquatic environments: a critical review". Royal Society Open Science. 5: 171792, May, 2018. 
[18] M, Peplow. "The plastics revolution: how chemists are pushing polymers to new limits". Nature. Aug, 2016. Available at: http://www.nature.com/news/the-plastics-revolution-how-chemists-are-pushing-polymers-to-new-limits-1.20433 [Accessed 25 Oct. 2017].

[19] M, Emadian, O, Turgut, and D, Burak. "Biodegradation of bioplastics in natural environments". Waste Management. pp.526-536. Jan, 2017.

[20] J, Wróblewska-Krepsztul, T, Rydzkowski, G, Borowski, M, Szczypiński, T, Klepka, and V, Thakur. "Recent progress in biodegradable polymers and nanocomposite-based packaging materials for sustainable environment". International Journal of Polymer Analysis and Characterization. pp 383-395. Mar, 2018.

[21] W, Wang, C, Hostettler, F, Damberger, J, Kossmann, J, Lloyd, and S, Zeeman. "Modification of Cassava Root Starch Phosphorylation Enhances Starch Functional Properties" Frontiers in Plant Science. 9:1562, Oct, 2018.

[22] T, Ogunrinola, and U, Akpan. "Production of Cassava Starch Bioplastic Film Reinforced with Poly-Lactic Acid (PLA)" International Journal of Engineering Research and Advanced Technology. pp 56. Aug, 2018.

[23] A, Ahmed, C, Zhang, and Q, Liu. "Comparison of Physicochemical Characteristics of Starch Isolated from Sweet and Grain Sorghum”. Journal of Chemistry. Vol. 2016, Article ID 7648639, 15 pages, 2016.

[24] M, Sapper, P, Talens, and A, Chiralt. "Improving Functional Properties of Cassava Starch-Based Films by Incorporating Xanthan, Gellan, or Pullulan Gums". International Journal of Polymer Science. vol. 2019, Article ID 5367164, 8 pages, 2019.

[25] V, Koester, V. "Plasticizers - Benefits, Trends, Health, and Environmental Issues". Chemistry Views. May, 2015.

[26] A, Edhirej, S, Sapuan, M, Jawaid, and N, Zahari. "Effect of various plasticizers and concentration on the physical, thermal, mechanical, and structural properties of cassava-starch-based films'. Starch. Volume 69, Issue1-2, April, 2016.

[27] P, Jantrawut, T, Chaiwarit, and K, Jantanasakulwong. "Effect of Plasticizer Type on Tensile Property and In Vitro Indomethacin Release of Thin Films Based on Low-Methoxyl Pectin". Molecular Diversity Preservation International and Multidisciplinary Digital Publishing Institute. pp 2. Jul, 2017.

[28] S, Maulida, M, Siagian, and P, Tarigan. "Production of Starch Based Bioplastic from Cassava Peel Reinforced with Microcrystalline Celllulose Avicel PH101 Using Sorbitol as Plasticizer". J. Phys.: Conf. Ser. 710 012012, 2016.

[29] D-Fructose [Internet]. Pubchem.ncbi.nlm.nih.gov2018. Available from: https://pubchem.ncbi.nlm.nih.gov/compound/D-Fructose [Accessed 21 Jun 2018]

[30] Glycerol [Internet]. Pubchem.ncbi.nlm.nih.gov2018. Available from: https://pubchem.ncbi.nlm.nih.gov/compound/753 [Accessed 21 Jun 2018]

[31] Food Ingredient \& Packaging Terms [Internet]. U.S. Food and Drug Administration2018. Available from: https://www.fda.gov/food/food-ingredients-packaging/food-ingredient-packaging-terms [Accessed 21 Jun, 2018]

[32] A, Edhirej, S, Sapuan, M, Jawaid, N, Zahari. "Preparation and Characterization of Cassava Starch/Peel Composite Film," Polymer Composites. Volume39, Issue5, Pp 1704-1715, May 2018.

[33] M, Sanyang, S, Sapuan, M, Jawaid, M, Ishak, and J, Sahari. "Effect of plasticizer type and concentration on physical properties of biodegradable films based on sugar palm (Arenga pinnata) starch for food packaging," Journal of Food Science and Technology., Volume 53, Issue 1, pp 326-336, January 2016.

[34] T, Abolibda. "Physical and Chemical Investigations of Starch Based Bio-Plastics". University of Leicester. Aug, 2015. Available at: https://lra.le.ac.uk/handle/2381/33021 [Accessed 25 Jun 2018]

[35] R, Sujuthi, and K, Liew. "Properties of Bioplastic Sheets Made from Different Types of Starch Incorporated With Recycled Newspaper Pulp". Transactions on Science and Technology. pp. 257-264. Jun 2016.

Publish your research article in AIJR journals-

$\checkmark$ Online Submission and Tracking

$\checkmark$ Peer-Reviewed

$\checkmark$ Rapid decision

$\checkmark \quad$ Immediate Publication after acceptance

$\checkmark$ Articles freely available online

$\checkmark \quad$ Retain full copyright of your article.

Submit your article at journals.aijr.in
Publish your books with AIJR publisher-

$\checkmark \quad$ Publish with ISBN and DOI.

$\checkmark$ Publish Thesis/Dissertation as Monograph.

$\checkmark$ Publish Book Monograph.

$\checkmark$ Publish Edited Volume/ Book.

$\checkmark$ Publish Conference Proceedings

$\checkmark \quad$ Retain full copyright of your books.

Submit your manuscript at books.aijr.org 